\section{A CASE OF PROSTATIC ABSCESS.}

BY RICKMAN J. GODLEE, M.S., F.R.C.S., ASSISTANT-SURGEON TO UNIVERSITY COLLEGE HOSPITAL.

THE clinical features of prostatic abscess are often so obscure and apparently anomalous that a short account of the following case may, perhaps with advantage, be placed on record.

A. B- aged forty-eight, but quite grey, and looking rather older than his real age, was armitted into University College Hospital on Sept. 25th, 1879. His first symptoms occurred in August, 1879, and consisted simply of an indefinite pain in the penis and some discomfort between his legs and at the lower part of the back. Cold compresses were applied and the pains disappeared, but returned at the end of eight or ten days more severely, accompanied by increased frequency of micturition, especially at night. These symptoms increased in severity, and about this time a small stone was passed, which the patient described as of the size of the end of a wooden match. After the passage of the stone he was relieved, but a slight purulent discharge occurred from the urethra. The relief, however, was ouly temporary, and early in the month of August he consulted Dr. Pomian, of Stoke Newington. Some cystitis then existed, but not to any great extent. A catheter and a sound were introduced on more than one occasion, and once a little blood followed the withdrawal of the instrument.

The dysuria increased about this time very much, so that when I saw him he had an irrepressible desire to micturate sometimes as uften as every twenty minutes, night and day. Theseattempts were accompanied by most agonising pain, and, moreover, were very ineffectual, so that it was absolutely necessary to pass a catheter three or four times a day. On passing the sound an obstruction was met with close to the neck of the bladder; the instrument was also turned over slightly to the right side as it entered the bladder. Sounding caused the patient intense pain; no stone was felt, but a little blood and pus appeared on the end of the instrument. An examination of the rectum showed that the prostate was slightly enlarged and hard, the enlargement being somewhat greater upon the left side. The urine was measured during one period of twenty-four hours; it amounted to 76 ounces, sp. gr. 1010, light in colour, somewhat turbid, throwing down a white deposit of phosphates, a little pus, and a very little mucus ; reaction acid; a trace of albumen; no casts. His temperature on admission was normal.

I may now describe together the symptoms up till October 16th.-Probably as a result of the sounding the patient had an attack of orchitis, which sent his temperature up to $102^{\circ}$ and $103^{\circ}$, and gradually subsided. The painful and spasmodic micturition varied a little from time to time, but continued a most distressing symptom, and necessitated the daily use of the catheter; the introduction of which required increasing care from the fact of the existence of an obviously increasing obstruction to the left side of the neck of the bladder. The character of the urine remained unchanged. The patient had three well-marked rigors, one on the $3 \mathrm{rd}$, one on the $4 \mathrm{th}$, and one on the $9 \mathrm{th}$. During these rigors the temperature rose to about $104^{\circ}$, at other times it was nearly normal. During this period, but especially after the rigors, his tongue became furred and dry, his pulse quick, he had an anxious worn appearance, and emaciated rapidly. The prostate was frequently examined, and there was an unmistakable increase in its size, especially in that of the left lobe, which extended, moreover, in the direction of the anus, and on introducing a sound on Oct. 11th I was struck with the thickness of tissue to be felt bencath the instrument by the finger introduced into the rectum. A little tenderness appeared on deep pressure in the perineum in front and to the left of the anus, but no swelling at any time. At last, on Oct. 16th, I felt sure that a sort of fluctuation existed at one point. The patient was accordingly chlorofurmed, and after placing him in the lithotomy position, a perforated needle was plunged into the soft spot through the rectum. This showed the existence of pus, and a guarded knife introdoced in the same way gave exit to about an ounce of matter. From that moment all the symptoms disappeared.
He had, $I$ believe, slight pain in the penis on two occrsions a few days atterwards, but this very soon passed off, and when I saw him last, on Jan. 12th, 1880, the prostate had nearly if not quite regained its normal dimensions, and the patient declared himself absolutely free from symptoms, and better than he had heen for ten years previously.

It should be added that the medical treatment of the case consisted in giving purgative medicines, which were constantly required, and in the administration of bicarbonate of soda, tincture of hyoscyamus, and extract of belladonna. Hot fomentations were applied to the lower part of the abdomen and the perineum.

The etiology of the case probably is as follows: the stone which was passed was most likely prostatic; its presence or its dislodgment set up the prostatitis and consequent slight cystitis, and this resulted in the abscess. It must be remembered, however, that the abscess may have resulted from a wound of the inflamed prostate in the course of instrumentation. Whether or not I followed the right practice in opening it through the rectum is, I am aware, open to doubt. The possibility of such an abscess opening secondarily into the bladder, and setting up that most intractable of conditions-a recto-vesical fistula-cannot be put out of view. The alternative, of course, is to introduce a long thin knife through the perineum, and endeavour to hit the pus in this way. This might be preceded by exploration with a fine trocar. It is also very questionable whether with such symptoms as I have described it would not be advisable to make an earlier exploration with a knife or trocar. The pus, no doubt, had existed some time before it was evacuated, though, from the nature of the case, its detection was difficult. It seems likely that the larger the abscess is allowed to become the greater will be the chance of the formation of a recto-vesical fistula. I am sorry I did not administer opium pretty freely.

\section{CONSTIPATION VIEWED AS A DISEASE 'PER SE' AND AS AN EXCITING CAUSE OF DISEASE.}

BY ROBERT BELL, M.D.,

PHYSICIAN TO THE GLASGOW INSTITUTION FOR DISEASES OF WOMEN AND CHILDREN.

IT is my intention in this communication to bring under the notice of the profession a casus morbi which I venture to say, although it is hardly ever overlooked, does not as a rule receive the attention it deserves; and, consequently, it might very often as well be iguored altogether as have bestowed upon it the passing notice so frequently accorded it. My observations extend over a period of six years, and the cases quoted are selected from a list of over two hundred. It does seem strange to meet with individuals almost daily who have been under treatment for weeks and months, and in many instances for years, and all this without any relief being experienced, when a little judicious treatment at the commencement of the symptoms of prostration might have prevented much of the suffering that has ensued, and have afforded speedy relief.

If we remember the power that the colon possesses of absorbing fluids (which numerous experiments place beyond a doubt), we do not require to ask an explanation as to the disappearance of the watery constituent of the stools in subjects suffering from constipation. I have heard it stated by a lecturer on the practice of medicine that "it was quite compatible with health to go a week, or even longer, without having an evacuation of the bowels"-that, in fact, it was all a matter of habit. Now, my observations go entirely to disprove such statements; moreover, such remarks are most apt to lead a student to look upon constipation as quite a trivial matter. If he does so, he will doubtless find that he has a great deal to unlearn, as he will soon discover that quite a host of complaints in every period of life may directly or indirectly take their origin in this abnormal condition of the bowels, and in very many instances the 